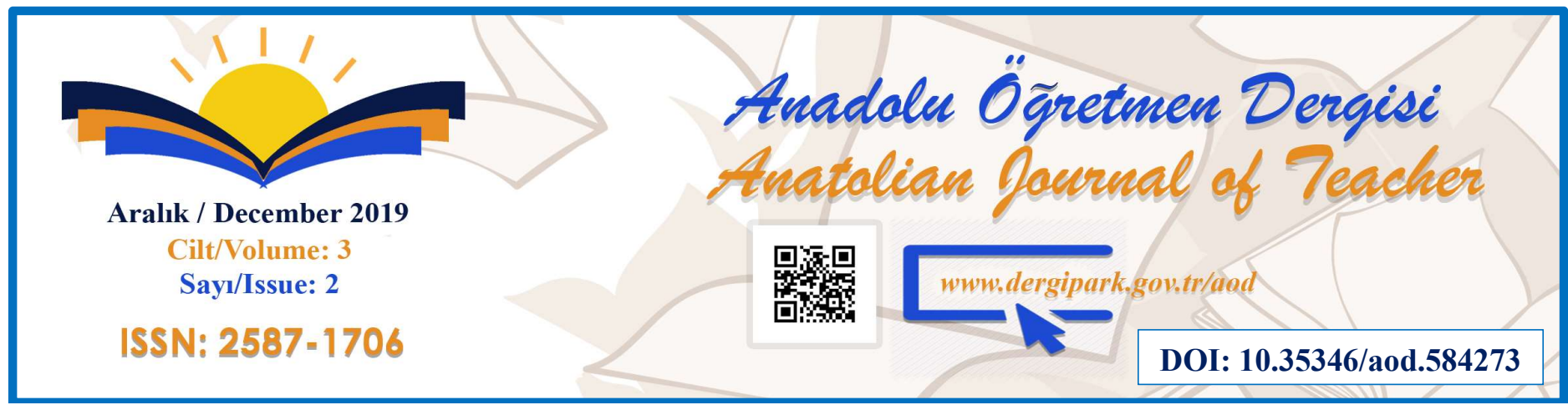

\title{
HIZLANDIRICILAR İLE GÜÇLENDİIILMIŞ SU ROKET TASARIMI
}

\section{Necati KARACA* Ahmet KARAGÖN**, Koray KESKIIN***, Alihan KUŞ ${ }^{* * * *}$, Hv. Müh. Tğm. Mert SEVER ${ }^{* * * * *}$, Doç. Dr. Ümit Deniz GÖKER ${ }^{* * * * * *+}$}

*Millî Savunma Üniversitesi, Hava Harp Okulu, Havacılık ve Uzay Mühendisliği Fakültesi, 34149, Yeşilyurt, İstanbul,2509karaca@harbiyeli.hho.edu.tr

** Millî Savunma Üniversitesi, Hava Harp Okulu, Havacılık ve Uzay Mühendisliği Fakültesi, 34149, Yeşilyurt, İstanbul,2501karagon@harbiyeli.hho.edu.tr

${ }^{* * *}$ Millî Savunma Üniversitesi, Hava Harp Okulu, Havacılık ve Uzay Mühendisliği Fakültesi, 34149, Yeşilyurt, İstanbul, 2502keskin@harbiyeli.hho.edu.tr

${ }^{* * * *}$ Millî Savunma Üniversitesi, Hava Harp Okulu, Havacılık ve Uzay Mühendisliği Fakültesi, 34149, Yeşilyurt, İstanbul,2518kus@,harbiyeli.hho.edu.tr

${ }^{* * * * *}$ Millî Savunma Üniversitesi, Hava Harp Okulu, Havacılık ve Uzay Mühendisliği Fakültesi, 34149, Yeşilyurt, İstanbul, 374msever@hho.edu.tr

****** Millî Savunma Üniversitesi, Hava Harp Okulu, Havacılık ve Uzay Mühendisliği Fakültesi, 34149, Yeşilyurt, İstanbul, udgoker@,hho.edu.tr

+Millî Savunma Üniversitesi, Hava Harp Okulu, Temel Bilimler Bölümü, 34149, Yeşilyurt, İstanbul

\section{ÖZET}

$\mathrm{Bu}$ çalışmamızda, ana roketten ayrılacak olan hızlandırıcılara sahip bir su roketi modelinin teorik olarak tasarımı yapılmış ve bu tasarım için en uygun parametre değerleri belirlenmiştir. Bu roket yapısı tasarlanırken, önce temel su roketi yapısına ve nasıl hazırlanıldığına değinilmiş ve sonrasında da hızlandırıcılara sahip su roket yapısı detaylı bir şekilde anlatılmıştır. Bununla birlikte, tasarlayacağımız su roketi için MATLAB programıyla analitik hesaplamaya gidilmiştir; farklı başlangıç parametreleri (kullanılan malzeme, roket parçalarının ebatları, eklenecek roket parçaları $v b$.) girilerek farklı kalkış parametre değerleri ve sonuçları hesaplanarak, bu sonuçları veren bir tablo hazırlanmıştır. Bu çalışmada, lise öğrenimi düzeyindeki öğrencilerin fizik dersinde rahatlıkla uygulamaya koyabilecekleri su roketinin yapımında kullanılacak parametrelerin verilmesi amaçlanmıştır.

Anahtar Kelimeler: Su Roketi, Hizlandırıcılar, Analitik Hesaplama

\section{THE DESIGN OF WATER ROCKET POWERED BY BOOSTERS}

\begin{abstract}
In this study, a theoretical water rocket model with boosters to be separated from the main rocket is made and exact physical parameters for this model is calculated. While designing this rocket, the basic water rocket structure and how it was prepared is discussed throughout the study and then the water rocket structure with accelerators is explained in detail. Besides, analytical calculation with MATLAB programme is carried out for the water rocket that we designed. A table is prepared by calculating different departure parameter values and results for given different initial parameters (used material, dimensions of rocket parts, rocket parts to be added, etc.). In this study, it is aimed to give the parameters that will be used in the construction of the water rocket that can be easily implemented in physics class by high school students.
\end{abstract}

Keywords: Water Rocket, Boosters, Analytical Calculation 


\section{GİRIŞ}

En basit haliyle, bir su roketi temelde, bir "burun" konisine sahip olan ve bazı kanatçıklar ilâve edilmiş, baş aşağı duran bir gazlı içecek şişesidir. Burun konisinin görevi, gazlı içecek şişesinin keskin burun ucunu daha aerodinamik hale getirmektir. Ayrıca roketimizde "taşıma yükü” veya paraşüt mekanizması varsa, muhtemelen konumlandırılacak yer bu bölgedir. Kanatçıklar, roketin karakterini belirleyen elemanlardır. Teknik olarak, kanatçıklar roketin sarsıntısız bir şekilde uçmasını sağlamak için önemlidir. Burun konisi ve kanatçıkların konumlandırılmasının sonucunda, şişe, hacmine eklenen suyu içerisinde muhafaza edecek ve istenildiğinde bırakabilecek bir salma mekanizmasına ihtiyaç duyulmaktadır. Bu aynı zamanda roketin tetikleme sistemi olarak çalışacaktır. Böylece, şişe içerisinde yüksek basınç değerlerine ulaşan su, tetikleme sonrası yüksek itkiyle şişenin ağzından (nozzle) hızla boşalacak ve roketi harekete geçirecek olan gerekli itkiyi üretecektir. Bu işlemin gerçekleşmesi için gerekli olan basınç değerini elde edecek şekilde, şişe, yaklaşık olarak 1/3 ile 1/4 oranında suyla doldurulmalıdır (De Podesta, 2007).

$\mathrm{Su}$ roketini firlatmak için rokete hava pompalanması gerekmektedir. Hava girerken, suyun içinde kabarcıklaşır ve suyun üzerindeki boş alanlara basınç uygular. Bu durumda, serbest bırakma mekanizmasının akıllıca tasarlanması gerekir; şöyle ki, roketin içine havanın girmesine izin verirken, aktive olana kadar suyun kaçmasına izin vermediği gözlemlenmelidir. Tetik, serbest bırakma mekanizmasını çalıştırdığında, içindeki basınçlı hava suyu nozzle içerisine iterek roketin fırlamasını sağlar. Böylelikle saniyede $30 \mathrm{~m}$ gibi bir roketin ulaşması kolay olmayan hızlara ulaşabilir. Fakat havaya böyle bir roketi firlatmak tehlikeli olabilmektedir (De Podesta, 2007). Su roketinin güvenli bir şekilde fırlatılmasını sağlamanın iki yolu vardır: İlk yöntem, roketin inişini yavaşlatmak için paraşüt ya da benzeri bir alete ihtiyaç duyulur. Fakat doğru zamanda açılacak paraşütü bulmak ya da tasarlamak oldukça zordur. yöntem, roketi firlatan için çok fazla sorun oluşturmasa da roketin firlatma istikametinde bulunan diğer canlılar için yine de tehlike yaratabilir. Açılı firlatmanın en iyi özelliklerinden biri, su roketinin oldukça etkileyici mesafelere ulaşabilmesidir. 30 veya $40 \mathrm{~m}$ 'ye ulaşmak kolay olabilir fakat $100 \mathrm{~m}$ üzerindeki mesafeler bazı dikkatli ve ayrıntılı tasarımlarla mümkündür. Bir açıyla roketi firlatma ile ilgili temel sorun, roketin düzgün bir şekilde uzun mesafelere gidemiyor oluşudur. Nozzle itkisiyle çok hızlı şekilde harekete geçen roket, istikametinden sapma eğilimleri gösterecektir. Bu problemi çözmenin iki standart yolu vardır: Fırlatma Rampass ve Firlatma Borusu. Bir firlatma rampası, firlatmadan önce ve firlatmadan hemen sonra, ihtiyaç duyulan hıza ulaşıncaya kadar roketin ağırlığını destekler (De Podesta, 2007).

Fırlatma borusu, roketin ağzından geçen bir tüptür. Tetik, serbest bırakma mekanizmasını etkinleştirdiğinde, roket, "serbest uçuşa" tam olarak ulaşmadan önce firlatma borusu boyunca kayar. Bunun iki avantajı vardır. İlk ve en belirgin avantaj1, firlatma borusunun firlatmadan hemen sonra roketin "kaymasını" önlemesidir. Bu bakımdan bir tür "iç firlatma rampası" gibi davranır. İkinci avantaj pek belirgin değildir. Tetik etkinleştirildikten sonra, roket içindeki yüksek basınçlı gaz genişler ve roketi firlatma borusu boyunca iter. Roket, firlatma borusu boyunca kayarken hızlanır 
ve fırlatma borusundan çıktığında oldukça hızlı hareket edebilir. Ancak, fırlatma tüpü içindeyken su kaybetmez. Bu, rokete bir tür "hareketli başlangıç" verir ve su yükünün daha verimli kullanmasını sağlar. Bu önemli ölçüde geliştirilebilir bir performanstır (De Podesta, 2007).

\section{YÖNTEM}

\section{Temel Bir Su Roketi}

İki litrelik bir gazlı içecek şişesi, roketin ana gövdesini oluşturacaktır. Sadece gazlı içecekler içeren şişeler kullanıldığından emin olunmalıdır. Gazlı içecek şişeleri, son derece güçlü olan PET'ten (Polietilen Tereftalat) yapılır. Bir tenis topu veya yaklaşık $60 \mathrm{gr}$ ağırlığındaki lastik top burnun ana bölümünü oluşturacaktır. Oluklu mukavva ya da daha iyi performans için oluklu plastik, kanatçıkların yapımında kullanılacaktır. İlk olarak; bir gazlı içecek şişesindeki gazlı içecek boşaltılmalı, etiketlerden kurtunulmalı ve suyla durulanmalıdır. Öncelikle, burun ve kanatçıkları ekleyerek işleme başlanmalıdır. Burun konisinin biraz keskin olması gerekmektedir ve daha sonraki bölümlerde göreceğimiz gibi, roketin önüne doğru biraz ağırlık yüklenmesi önemlidir. Bu gerekli tasarıma tenis topunu şişenin dibine bantlamak suretiyle ulaşılabilir (De Podesta, 2007).

İhtiyaç duyulan oluklu plastikler, genelde tabela yapımında kullanılan Corriflute (Oluklu sunta ile benzer bir yapıya sahip, yüksek etkili polipropilen reçineden üretilen karşılıklı sıkıştırılmış bir plastik levhayı ifade eder. Hafif fakat sert bir malzemedir. Tipik olarak çok çeşitli renk ve kalınlıklarda bulunmaktadırlar (oldukça yaygın olarak 3, 4, 5 mm)) adı verilen malzemeden kesilebilir. Bu malzeme su geçirmezdir ve hafif olmasına rağmen yüksek sertliğe sahiptir. Oluklu mukavva da diğer bir alternatif olabilir fakat bir kaç firlatmadan sonra maruz kaldığı su yüzünden sslanacak ve performans kaybına uğrayacaktır. Yine de birçok ambalaj malzemesi ile bu ihtiyaç giderilebilir (yüksek sertlik-ağırlık oranı). Yaygın olarak, eski CD’ler de tercih edilebilir ve gerekli şekillerde kesilerek gövdeye sabitlenir. Fakat CD’nin keskin yapısının verebileceği zararlar göz önüne alındığında, keskin kenarlarının bantlanarak kapatılması tavsiye edilir. Kanatlar da basitçe roketin kenarına bantlanmalıdır. Fırlatma sırasında sökülmelerini engellemek için sağlam bir şekilde tutturulmaları gerekmektedir. Kanatlar inişlerde kesinlikle hasar görecektir, ancak daha sonra tamir edilmesi zor olmayacaktır. Tüm kanatçıklar birbirlerinin aynısı olmalıdır ve nozzle’a yakın olacak şekilde konumlandırılmalıdır, bununla birlikte kanatçıklar gövdeye simetrik olarak sabitlendirilmelidir (3 kanatçık 120 derece, 4 kanatçık 90 derece) ve kanatçık profilleri ince olmalıdır (De Podesta, 2007).

Fırlatıcılar, roketlerden daha karmaşıktır ve bir firlatıcı yapmak bir roket yapmaktan daha uzun sürer. Şişenin nozzle kısmına konumlandırılan özel ağızlar da kullanılabilir. Nozzle, normal bahçe hortumu bağlantı parçalarına uyacak şekilde biçimlendirilmelidir ve sistem, normal bahçe hortumu bağlantılarına dayanan hızlı bir serbest bırakma ile birlikte ve bir bisiklet fren kablosuna dayanan bir sistemle etkinleştirme 
mekanizması halinde olmalıdır. Roketi firlatıcıya bağlamak ve bir firlatma mekanizması tasarlamak en zor kısmıdır. Tasarlamak için iki yol izlenebilir:

Tasarım A: Tasarım A, birbirine lehimlenmiş standart $15 \mathrm{~mm}$ bakır su tesisatı borusundan üretilmiştir. Lehimleme muhtemelen yeni başlayanlar için oldukça zordur, bu nedenle, alternatif olarak başlatıcı, sıkıştırma parçaları (anahtarlarla, basınç uygulayarak sıkı bir şekilde yapılabilir) veya "itme fit" parçaları (ek alet gerektirmeyen) kullanılarak yapılabilir. Bununla birlikte, tasarım, bağlantı parçalarının küçük detaylarına bağlıdır, bu nedenle seçilen bağlantı parçalarında neyin işe yarayıp neyin işe yaramadığının kontrol edilmesi gerekmektedir. Bu tasarımda, şişenin dış kısmındaki vida dişi, pürüzsüz bir yüzey elde etmek için zımpara kâğıdı ile çıkarılır. Bu işlem elle yapılabilir, ancak şişeyi döndürerek ve kum kâğıdı ile hafif bir baskı uygulayarak çok daha iyi bir sonuç elde edilebilir (De Podesta, 2007).

Tasarım B: Tasarım B'de, destek eklemek ve tasarım sırasında ekstra momentum vermek için bir firlatma borusu kullanılır. Standart $22 \mathrm{~mm}$ çapında plastik sıhhi tesisat borusu ve 21,5 $\mathrm{mm}$ çapında plastik "taşma" borusu çok basit sıkı geçirmeli tesisat bağlantıları kullanılarak monte edilirler. Bu tasarımda, standart bir şişe kapağında $22 \mathrm{~mm}$ çapında bir delik açılır. Şişenin üst kısmı ile tüp arasında bir "O” halkası hapsedilmelidir. Bu borunun duvarına doğru basınç geçirmez bir kayar conta konmalıdır. Genelde, standart $22 \mathrm{~mm}$ tesisat boruları PET şişenin boynuna uymaz. Bu nedenle, doğru boru tipini aldığımızdan emin olmak için, satın almadan önce borunun uygun olup olmadığını kontrol etmek amacıyla bir şişe alınır ve şişenin tüpe sıkıca oturması durumunda zımpara kâğıdı kullanılarak çapı hafifçe azaltılır.

Şişenin kolayca kaymasını sağlamak için az miktarda yağlama yağı veya gresi eklenmesi gerekebilir. $\mathrm{Bu}$ tasarımlara ilişkin daha kapsamlı ve görsel içerikli bilgi Karagön ve ark. (2019) tezinden incelenebilir. Fırlatıcı tasarımının son bir özelliği su roketine basınç vermek için kullanılan pompa seçimi ile ilgilidir. Genel olarak üç tip pompa mevcuttur: El pompaları, ayak pompaları ve üzengi pompaları. Bunlardan herhangi biri kullanılabilir, ancak seçtiğimiz herhangi bir pompanın "olması gereken” özelliği roketimizin nasıl performans göstereceği konusunda bize bilgi verecek olan bir basınç göstergesidir (De Podesta, 2007).

Roket testinde, firlatmadan önce roket özelliklerinin ve roket performansının ölçülmesi şarttır. Daha sonra hangi fırlatma özelliklerinin roketin performansını hangi şekilde etkilediğini bulmak için firlatma işlemi ve uçuş dinamiklerini anlamak gerekmektedir. Roketin boş ağırlığı, roketin içinde su olmadan ölçüldügünde sahip olduğu ağırlıktır ve tüm uçuş süresi boyunca değişmez. Yalnızca tek bir şişe tasarımında, toplam hacim etikette belirtilen hacme çok yakındır. Çok şişeli bir roketin inşa edilmesi durumunda ise muhtemelen bunu ölçmemiz gerekir. En kolay yol, roketin önce boş ve sonra suyla dolu halini tartmaktır. Fazladan her $g r, 1 \mathrm{~cm}^{3}$ suya veya her $\mathrm{kg} 1 \mathrm{lt}$ suya karşılık gelir. İyi bir başlangıç noktası, genellikle yaklaşık bir çeyrek suyla doldurmaktır. Optimum doldurma bir dizi faktöre bağlıdır, ancak genellikle \% 20 ila \% 30 aralığındadır. Fırlatma açısının $45^{\circ}$ den büyük olması daha iyi sonuç verir ama bu tasarlanan rokete göre 
değişkenlik göstermektedir. Basıncın arttırılması, firlatma sırasında depolanan enerjiyi arttırır, bu da roketin elde ettiği maksimum hızı arttırır ve bu sayede firlatma aralığı, uçuş süresi ve maksimum yükseklik de artacaktır. Fırlatma hızı arttıkça aerodinamik sürtünme de çok hızlı bir şekilde artar. Havada geçirilen süre, roket performansının iyi bir ölçüsüdür ve muhtemelen en iyi kronometre ile ölçülür (De Podesta, 2007).

\section{Roket Firlatma Sırasındaki Fiziksel Olaylar}

Bu bölümde roketin firlatılması sırasındaki fiziksel olaylar anlatılacaktır (Şekil 1). Sol sütunda, saniye cinsinden firlatmadan öncesi ve/veya sonrası için zaman verilmiştir; ortadaki sütun “neler olduğunu” gösterir ve sağ sütun ise yorumunu içerir. Boşken $100 \mathrm{gr}$ kütleli ve firlatma sırasında su ile dolu olan $2 l t$ ’lik bir roketin dikey olarak fırlatılacağını varsaydığımızda, alıntılanan hızlar ve yükseklikler örnek bir su roketi simülatörü için aşağıdaki gibidir (De Podesta, 2007). 
Karaca, N., Karagön, A., Keskin, K., Kuş, A., Sever, M. \& Göker, Ü. D. (2019). Hızlandırıcılar ile güçlendirilmişs su roket tasarımı, Anadolu Ögretmen Dergisi, 3(2), 198-213, DOI: 10.35346/aod.584273

\begin{tabular}{|c|c|c|}
\hline Zaman & Mekanizma & Yorumlar \\
\hline-60 saniye & $\begin{array}{l}\text { Tahliye } \\
\text { Mekanizması }\end{array}$ & $\begin{array}{l}\text { Roket doldurulur ve ardından ayağına } \\
\text { yerleştirilerek, pompalamaya başlanır. Hava } \\
\text { sıkıştırıldığında ısınır ve bunu pompanın çıkışına } \\
\text { yakın hissedebilmemiz gerekir. Bununla birlikte, } \\
\text { hava su içinde kabarcıklar halinde tekrar soğur ve } \\
\text { su roketindeki hava suyun sıcaklığına yakındır. }\end{array}$ \\
\hline-30 saniye & $\begin{array}{l}\text { atm. basincinda } \\
.5 \text { litre hava }\end{array}$ & $\begin{array}{l}\text { Seçilen firlatma basıncına ulaşılır. } \\
\text { Kullandığımız ayak pompasındaki ölçerin } 3 \mathrm{~atm} \\
\text { okuduğu varsayılacaktır. Başlamadan önceki } \\
\text { basınç } 1 \text { atm olduğundan, şişedeki havanın } \\
\text { gerçek basıncı şimdi } 4 \text { atm'dir. Basınçlı gaz, } \\
\text { roket için enerji kaynağıdır. İyi bir roket } \\
\text { tasarımı, depolanan maksimum enerji miktarını } \\
\text { roketin kinetik enerjisine dönüştürür. }\end{array}$ \\
\hline
\end{tabular}
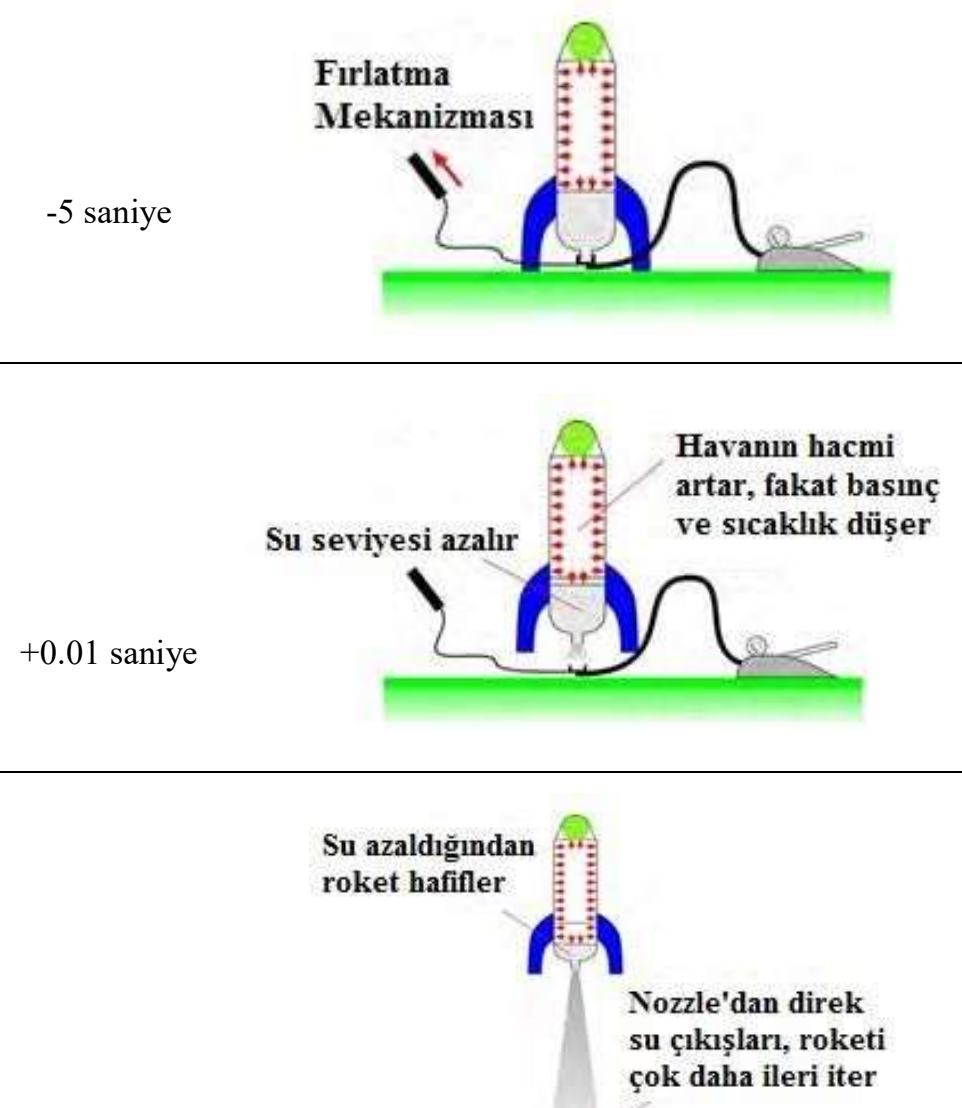

+0.1 saniye
Son firlatma uyarısı verilir ve her şey güvenliyse firlatma mekanizması serbest birakılır. Fırlatmadan hemen önce nozzle üzerindeki kuvvet çok büyüktür. Bu noktada $500 \mathrm{gr}(0,5 \mathrm{~kg})$ kütlesindeki $500 \mathrm{ml}$ su, roket kütlesinin çoğunu oluşturur.

Mandal serbest birakıldığında, gaz, suyu ağızlıktan dışarı iter ve roket kalkmaya başlar. Havanın basıncı düşmeye başlar ve hava büyüdükçe sıcaklığı da düşer. $10 \mathrm{~ms}$ sonra hız hala oldukça yavaştır çünkü roket hala içerisinde ağır bir su yüküne sahiptir.

Yarımdan biraz daha az miktarda su roketten ayrılmıştır. Roket yaklaşık $0,5 m$ yüksekliğe ulaşır ve saniyede yaklaşık $10 \mathrm{~m}$ hızla yukarı doğru hareket eder. Hızlanan roketin arkasında bir "boru su" izi görülmelidir. 
Karaca, N., Karagön, A., Keskin, K., Kuş, A., Sever, M. \& Göker, Ü. D. (2019). Hızlandırıcılar ile güçlendirilmişsu roket tasarımı, Anadolu Ögrretmen Dergisi, 3(2), 198-213, DOI: 10.35346/aod.584273

+0.22 saniye

Artık tüm su bitmiștir
Roket içindeki hava halen atmosferik basincin üstündedir

Tüm su artık roketi terk eder. Şişeden $500 \mathrm{ml}$ su almak için, bu işlem $10 s$ sürebilir. Şimdi hepsi saniyenin dörtte birinin altına inmiştir. Roket, saniyede $26 m$ hızla ilerler. Basınç 4 bar'dan 2,4 bar'a kadar düşer. Hava genişledikçe soğur ve yaklaşık $-19^{\circ} C^{\prime}$ dedir. Ancak yine de roket baskı altındadır ve çıkış su ile engellenmediğinden, hava roketten ayrılmayı sudan çok daha kolay bulmaktadır.

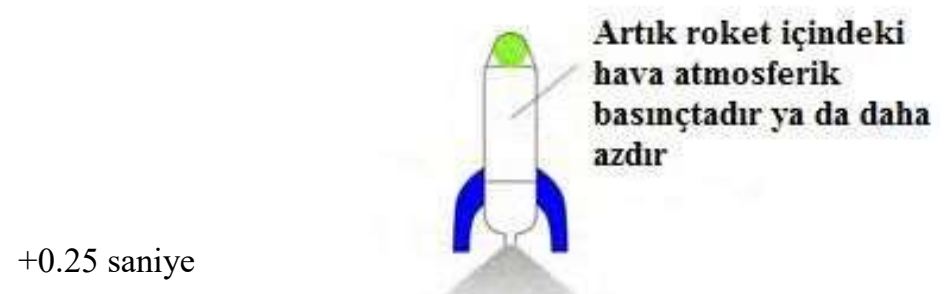

Roket içindeki

hava da hızh bir șekilde atılır
$30 \mathrm{~ms}$ 'den sonra, basınçlı hava rokete son bir destek vererek roketten ayrılır. $\mathrm{Bu}$ artış oldukça önemli bir etkiye sahip olabilir, çünkü roket firlatıldığından daha hafiftir. Bu fazın sonunda, roket saniyede yaklaşı $35 \mathrm{~m}$ olan maksimum hızla hareket etmektedir. Roket şimdi uçuşunun "seyir" veya "balistik" aşamasına girmektedir.

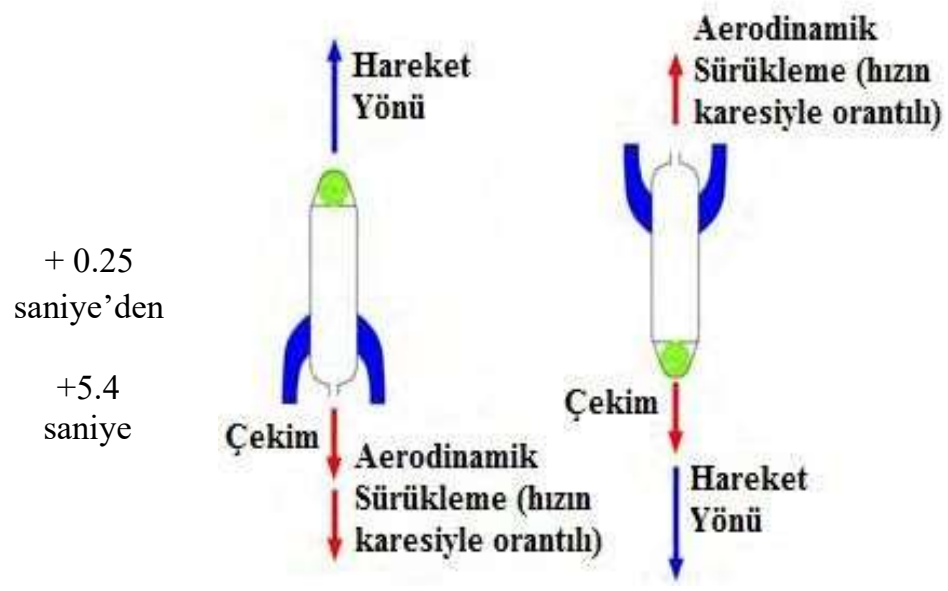

Uçuşun bu aşamasında artık rokete etki eden kuvvetler sadece yer çekimi ve aerodinamik sürükleme kuvvetidir. Yerçekimi her zaman roket üzerinde aşağı doğru hareket eder ve maksimum yüksekliği yaklaşık $34 m$ ile sınırlar. Roket daha sonra düşer ve saniyede yaklaşık 20 $m$ hızla ve yaklaşık 5,4 s sonra yere çarpar. Roket iyi tasarlanırsa, aerodinamik sürükleme daima hareket yönüne karşı hareket eder, bu nedenle sürükleme roket yükselirken aşağı doğru ve roket inerken yukarı doğru hareket eder. Roket o kadar iyi tasarlanmamıssa, aerodinamik kuvvetler rokete başka yönlerde etki edebilir ve takılmasına neden olabilir.

Şekil 1. Su Roketi Fiziğinin Aşamaları (De Podesta, 2007) 


\section{Roket Dinamiğgi}

Roketin dinamiği, rokete etki eden üç kuvvetin tahminleri yapılarak hesaplanır. İlk kuvvet yerçekimidir (gravity) ve büyüklüğü basitçe $\boldsymbol{m g}$ 'dir, burada $m$ roketin kütlesidir. Ancak, roket suyunu atarken roket kütlesinin uçuş sırasında değişeceği unutulmamalıdır. Bir sonraki kuvvet, itki (thrust)'dir. Şimdilik, itmenin roketin ekseni boyunca hareket ettiğini varsayıyoruz ve son kuvvet, forma sahip olan aerodinamik sürükleme (drag)'dir (Şekil 2).

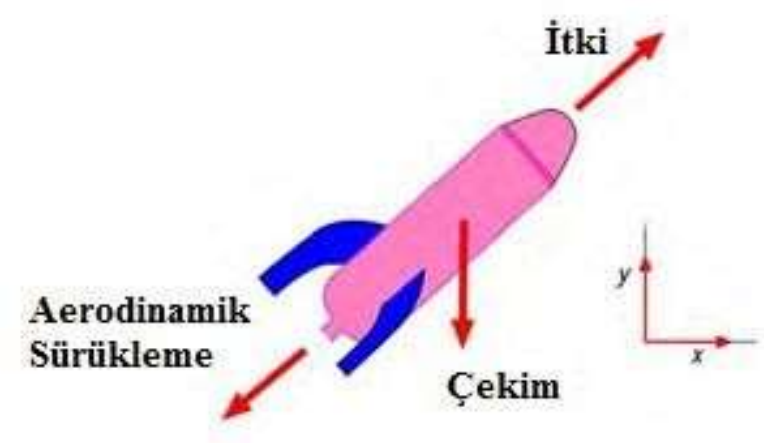

Şekil 2. Roket Dinamik Sistemi (De Podesta, 2007)

\section{HIZLANDIRICILARA SAHIP SU ROKETININ GENEL YAPISI}

Hızlandırıcıların roketten ayrılmalarının asıl amacı daha yüksek bir rakım elde etmek için ana roketin firlatma hızını arttırmaktır. Hızlandırıcılar, depolanan enerji harcandığında roketten otomatik olarak ayrılarak ölü ağırlık ve fazladan sürükleme değerlerinin minimuma inmesini sağlarlar. Hızlandırıcılar ve roketin ana gövdesi aynı anda firlatılır. Hızlandırıcılar roket gövdesine gevşek bir şekilde ve sadece geriye doğru hareket edebilecek biçimde tutturulur. Fırlatmadan itibaren gövdeyle birlikte itki sağlayarak, depolanan enerji tükendiğinde ise sürüklemenin etkisiyle roket istikametinin tersi yönünde roketten ayrılırlar. İtki enerjisi bitiminde, hızlandırıcı diğer hızlandırıcılardan bağımsız olarak ana gövdeden ayrılır. Hızlandırıcılar ana roketten daha fazla itki üretmelidir. Bu, daha büyük nozullarla veya ana roketten daha yüksek bir basınçla elde edilebilir (Köpük kullanımı, ana roket itme kuvvetini uzatmak için de kullanılabilir). Hızlandırıcılar ve ana roket aynı anda tetiklenmelidir. Her hızlandırıcının itme gücü uçuş boyunca diğer hızlandırıcılarla eşit olmalıdır. Bu, her hızlandırıcı için basınç, su hacmi ve kapasitenin eşit olması anlamına gelir (http://www.aircommandrockets.com/howitworks 1.htm). 
Özdeş şişe kullanımı ve aynı tasarım tekniği kullanılarak hızlandırıcı kapasiteleri eşit tutulabilir. Tüm nozulları aynı anda firlatmak için farklı mekanik teknikler kullanılabilir. Hem ana roketin hem de hızlandırıcıların nozulları tek bir kanaldan tutulabilir ve aynı anda serbest bırakılabilir veya ana roket ve farklı kanallardan kontrol edilip fırlatma işleminin eş zamanlı olması sağlanabilir. Ölçü kabı kullanılarak eşit miktarda su kolayca elde edilebilir. Hızlandırıcılar arasındaki basıncı eşitlemek biraz daha zordur. Bir manifoldun, hızlandırıcıları ortak bir hava kaynağına basitçe bağlandığı durum düşünülebilir. Böylelikle her hızlandırıcıya eşit miktarda hava akması sağlanabilir. Fakat yine de bu yöntem kendi başına çözüm olmayabilir. Her hızlandırıcı için geri dönüşsüz valfler kullanılarak bu durum potansiyel olarak düzeltilebilir, ancak yine de hızlandırıcılar arasında bir basınç farkı olabilir. Bunun sebebi geri dönüşsüz valflerin tamamen aynı basınçta kapanmamasıdır. Burada sunulan yöntemde, hızlandırıcıların hava odaları, sadece havayı değil suyu da aktaran bir açık hava manifoldu ile birbirine bağlanır. Hızlandırıcıların üst kısımlarındaki hava odalarını birbirine bağlayan küçük hortumlara sahip olmak mümkün olsa bile, hızlandırıcılar düşerken birbirlerine bağlı kalacaklardır. Bu durumda, hortumlar ana roketin kanatlarına takılabilir ve roketten ayrılma esnasında hızlandırıcılar birbirlerinden bağımsız hareket edemeyeceklerdir. Roket üzerinde hortumların ayrı olduğu bir hava manifoldu yapılabilir fakat bu da rokete gereksiz bir karmaşıklık ve ekstra ağırlık kazandıracaktır. Herhangi bir ayırma mekanizması tam basınca dayanabilecek yapıda olmalıdır. Bu nedenle, firlatıcı için basit bir hava manifoldu oluşturulması önerilir. Bunu başarmak için, her bir nozzle yuvasının nozzledan geçen ve hızlandırıcının su seviyesinin üzerine çıkan bir hava doldurma tüpüne ihtiyacı vardır (http://www.aircommandrockets.com/howitworks_1.htm).

\section{Hızlandırıcılara Sahip Su Roketinin Çalışma Prensibi}

$\mathrm{Bu}$ roket, hızlandırıcılar ve ana roket, nozzle için alt kısımda bir açıklık ve su ile doldurmak için üst kısımda bir açıklığa sahip olacak şekilde eklenmiş şişelerden yapılır (Şekil 3). Roket gövdesi tarafındaki tüpler, PL premium yapıştırıcı (İç ve dış mekânda, emici olan veya olmayan tüm yüzeylerde kullanılabilen, çivi ve vida gerektirmeden montaj yapılmasını sağlayan, poliüretan esaslı inşaat ve montaj yapıştırıcısıdır) ile şişenin yüzeyine yapıştırılır. Hızlandırıcılardaki pimler de PL premium yapıştırıcı ile hızlandırıcıların yüzeyine yapıştırılır. Bu örnekte, destek nozullar ana roket nozulden daha büyüktür. Hızlandırıcılar ilk olarak firlatıcıya yerleştirilir. Bunlar hava doldurma tüpleri üzerinde kayar ve alt kısımda bir halka ile kapatılır. Bu halka hızlandırıcıların belirli seviyeden sonra aşağı kaymamasını sağlar (Hızlandırıcıların herhangi bir şekilde kilitlenmediği ve hava doldurma borusunda yukarıya ve aşağıya hareket etmekte serbest oldukları unutulmamalıdır). Daha sonra ana roket fırlatıcıya yerleştirilir. Gövde üzerindeki halkaların, hızlandırıcı gövdesindeki pimlere tam olarak yerleştiğinden emin olunmalıdır. Ana roket, serbest bırakma mekanizmasına yerleştirilir. Hızlandırıcılar ve ana roket üst kısmından su ile doldurulur. Her hızlandırıcı da 
eşit miktarda su bulunur. Hava dolum tüplerinin üst kısımları, borunun su hattının yukarısında açılan küçük bir delik ile kapatılabilir. Bu, üstten doldururken suyun manifolda girmesini önler. Ana kademedeki hava besleme hattındaki geri dönüşümsüz valf, suyun hava manifolduna geri girmesini önler. Daha sonra tüm roket basınçlandırılır. Hava manifoldundaki açık kanal her iki hızlandırıcıya eşit miktarda hava ile dolmasına izin verir. Basınç arttıkça hızlandırıcılar roketi yukarı çekmeye başlayacaklardır. Ancak roket gövdesi üzerindeki pimlerle hızlandırıcılar tutulur. Fırlatma, ana roketin firlatıcıdan tetiklenmesiyle başlar. Bu, itki üreten her elemanın eş zamanlı olarak fırlatılmasını sağlar. Ana roketten daha büyük bir itme gücüne sahip olan hızlandırıcılar, pimleri tüplerin içinde tutarak her zaman roket gövdesini çekmeye çalışacaktır. Roket hareketine başlar başlamaz hava sürüklemesi rokete üstten etki etmeye başlayacaktır. Hava doldurma boruları ayrıca, takviyeleri güçlendirmek için bu durumda normal firlatma boruları olarak da işlev görür. Hızlandırıcıların itki kuvveti, ana roket itki kuvvetinden büyük olduğu için hızlandırıcıların düşmesi mümkün olmayacaktır. Uçuş esnasında hızlandırıcılardaki basınç ve itki kuvveti ana rokete göre daha hızlı azalacaktır. Roket, indüklenen sürükleme kuvvetini de arttırmaya devam edecektir. Hızlandırıcılarda harcanan basınç ile birlikte itki kuvveti de kaybolur ve artık boosterlara (hızlandırıcılara) etkiyen net kuvvet yerçekimi ve sürükleme kuvvetidir. Ana roket hızlanmaya devam edecektir. Hava basıncından kaynaklanan sürükleme kuvveti etkisiyle basınç ve itki kuvvetini tüketen hızlandırıcılar, roket gövdesinden ayrılıp düşeceklerdir. Ana roket, sürüklemeden daha fazla itki kuvveti ürettiği sürece yükselmeye devam edecektir.

Roket, ana faz için itici fazın hızlandırıcılara göre çok daha uzun olacağı şekilde tasarlanmalıdır. Bu, roket gövdesinin daha fazla hacim içermesi ve/veya daha küçük bir nozzle sahip olmasıyla başarılabilir. Ana rokete köpük eklenmesi de itme süresini uzatır. Borular ve pimler, çok kısa olmamalıdır. Eğer çok kısa olursa titreşim ve sarsıntıdan dolayı hızlandırıcıların erken ayrılmasına sebep olabilirler. Çok fazla kuvvet geçişine maruz kalacakları için pimler, tüpler ve roket gövdesi sağlam malzemelerden yapılmalıdır. Yükü yaymaya yardımcı olmak için 2 ya da daha fazla pim kullanımı düşünülebilir. Yüksek ivmelenmeyi ve pimlere etkiyen fazla kuvvet değerlerini azaltmak için hızlandırıcıların nozzleları daha küçük olacak şekilde tasarlanmalıdır. Rokete basınç uygulandığında, basınç altında esneklik gösteren malzemeler için hızlandırıcıların küçük dikey hareketleri olacaktır. Bu durum, tasarımda dikkate alınarak halka ve pimlerin kesitleri ve uzunlukları dikkatli seçilmelidir. Ana roketin nozzle çapındaki artış ve basınçlandırmadan sonra hızlandırıcılara dikkat edilmelidir. Ana roket, hızlandırıcılara göre daha ivmeli hareket ederse, hızlandırıcılardan hemen ayrılma durumu gözlemlenebilir. Fırlatıcı yuvaları iyi ayarlanmazsa roketin nozzlelarının fırlatma esnasında sıkışma durumu gözlemlenebilir. 


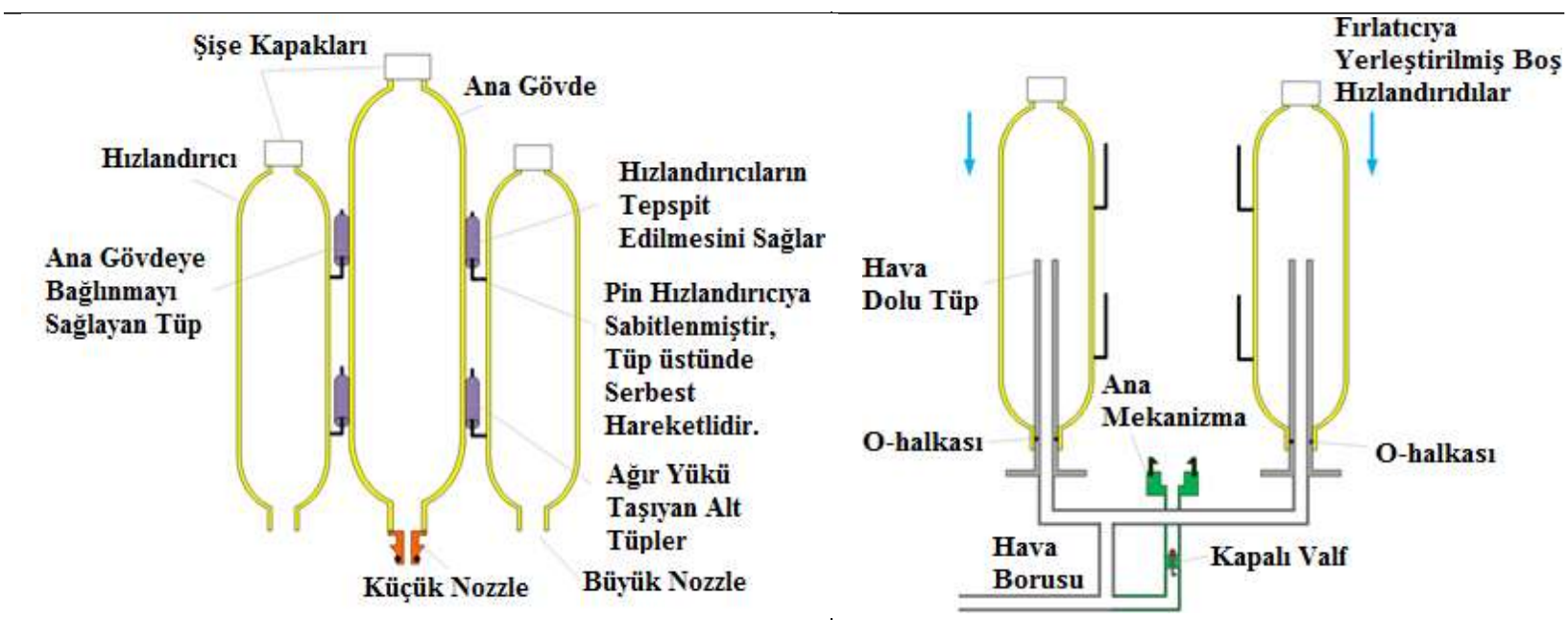

Roket Gövdesi ve Hızlandırılarıcıların Yerleştirilmesi

Hızlandırıcıların Fırlatıcıya Yerleştirilmesi

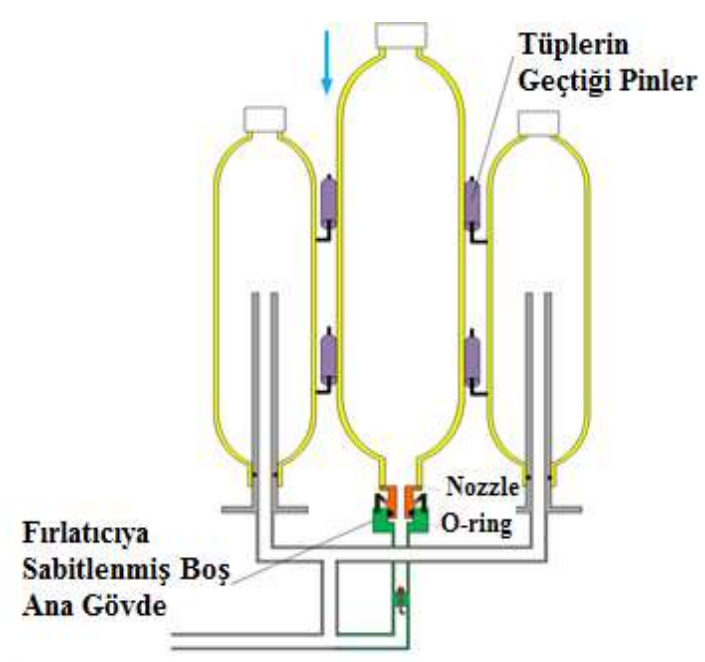

Ana Roketin Hızlandırıcıya Yerleştirilmesi

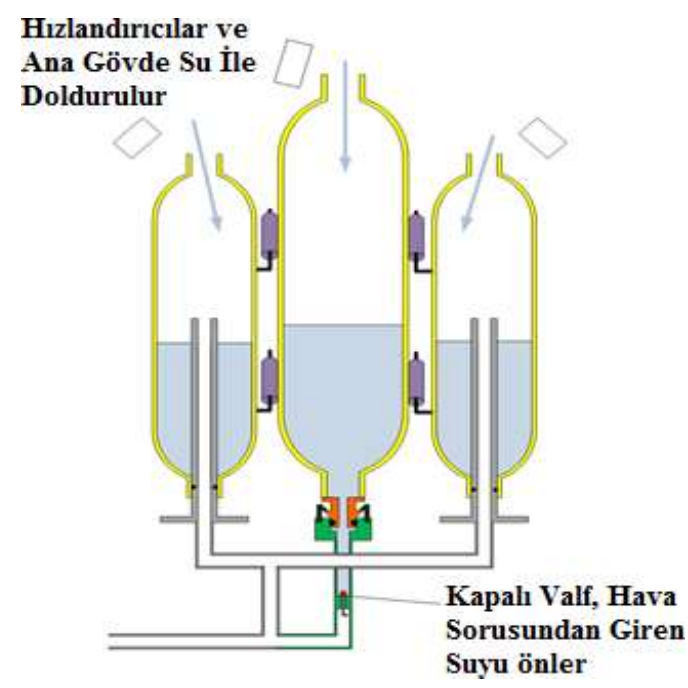

Hizlandırıcıların ve Ana Roketin Su İle Doldurulmas1 


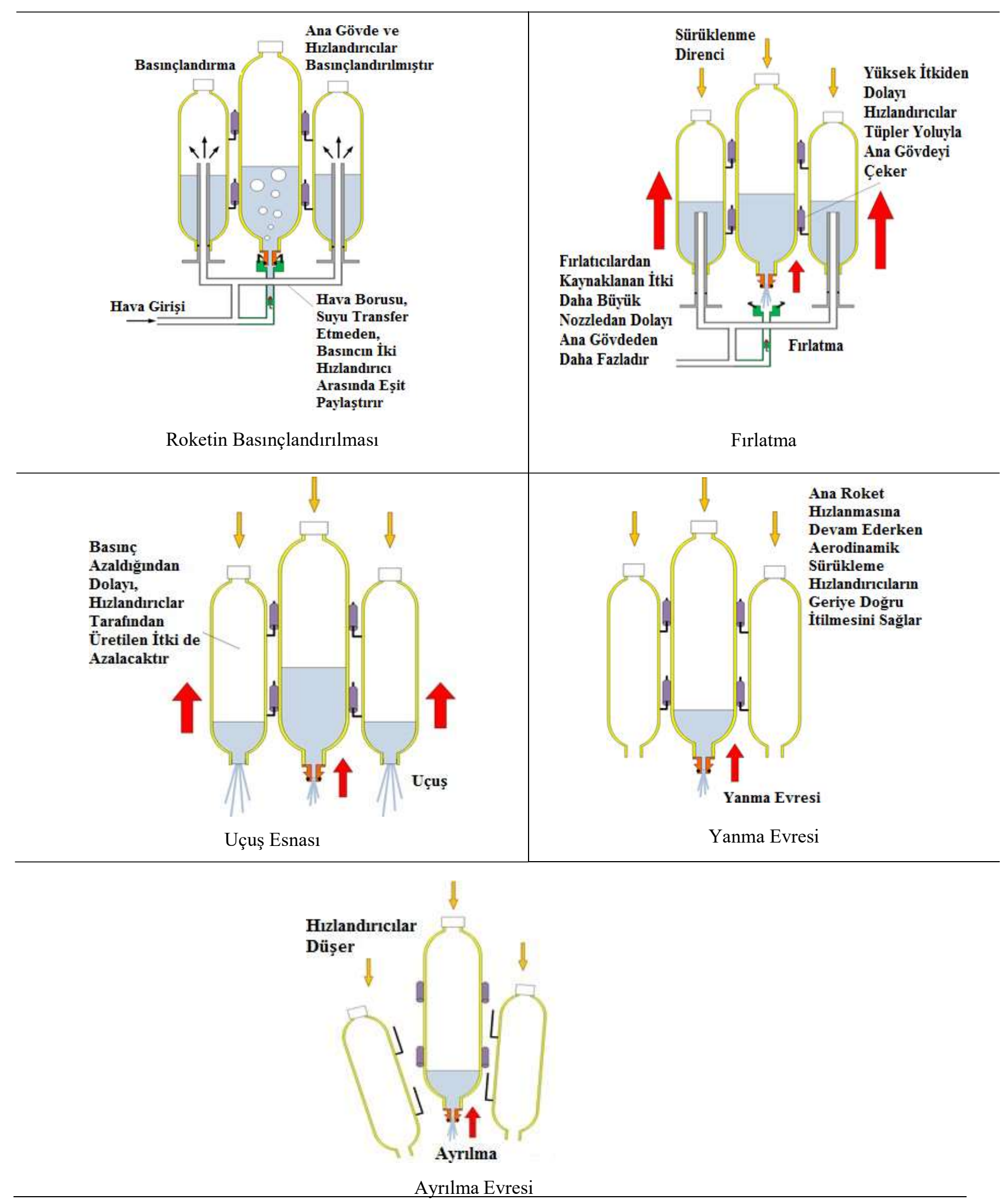

Şekil 3: Hızlandırıcılı Su Roketinin Çalışma Prensibi

(http://www.aircommandrockets.com/howitworks_1.htm). 


\section{SONUÇ}

Su roketi simülasyonumuzun kodu MATLAB programında hazırlanmıştır, burada kullandığımız parametreler ve denklem uygulamaları ise https://www.ppmhcharterschool.org/ourpages/auto/2016/8/15/43286719/Bottle\%20Rocket\%2

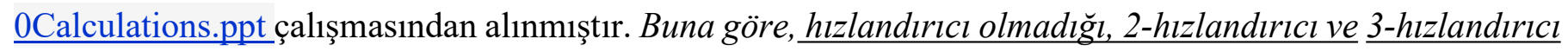
olduğunda su roketine ait MATLAB yazılımı sonuçları așağıdaki gibidir: Bu kodun analizinin sonucunda aşağıdaki grafik (Şekil 4) elde edilmiştir. Şekil 4'de hızlandırıcı olmadan, 2-hızlandırıcılı ve 3-hızlandırıcılı su roketinin verilen ilk açıya göre atış uzaklığının değişimi gösterilmektedir. Şekilde de görüldüğü gibi hızlandırıcı sayısını arttırdığımızda verilen aynı açı değerleri için atış uzaklığının arttığı görülmektedir. Eğer roketimizi 3-hızlandırıcı ile donatırsak, roketimizin ulaşacağı uzaklık en fazla olacaktır. Bu grafiği ve roketlerin ne kadar yükseğe çıkabileceklerinin hesaplanması Tablo 1'de verilen başlangıç ve bitiş parametlerinin değerleri ile hesaplanmıştır. Burada bağımlı değişken olan parametre menzil/uzaklık (range) olacaktır.

Tablo 1. MATLAB Kodundaki Başlangıç ve Bitiş Parametrelerinin Değerleri

\section{HIZLANDIRICI OLMADIĞI DURUMDAKİ PARAMETRELERİN DEĞERLERİ}

\begin{tabular}{ll}
\hline Suyun Yoğunluğu & $: 998 \mathrm{~kg} / \mathrm{m}^{3}$ \\
2 litrelik kola şişesinin egzoz yarıçapı & $: 0,0105$ \\
Sürtünme Katsayısı & $: 0,98$ \\
Başlangıç Basıncı & $: 40 \mathrm{psi}$ \\
Suyun Hacmi & $: 0,7 \mathrm{litre}$ \\
Suyun Kütlesi & $: 0,6986 \mathrm{~kg}$ \\
Roket Kütlesi & $: 0,3 \mathrm{~kg}$ \\
Toplam Hacim & $: 2 \mathrm{litre}$ \\
Başlangıç Hacmi & $: 0,3 \mathrm{litre}$ \\
Egzozun alanı & $: 0,000346 \mathrm{~m}$ \\
Bitiş Basıncı & $: 26 \mathrm{psi}$ \\
$\Delta P$ & $: 33 \mathrm{psi}=2,27 \mathrm{x} 10^{5} \mathrm{~N} / \mathrm{m}^{2}$ \\
Ortalama Kütle Akış Hızı & $: 7,2159 \mathrm{~kg} / \mathrm{sn}^{2}$ \\
Çıkış Hızı & $: 20,896 \mathrm{~m} / \mathrm{sn}^{2}$ \\
İtki & $: 150,78 \mathrm{kgm} / \mathrm{sn}^{2}$ \\
Sürtünme Kuvveti & $: 0(\mathrm{Başlangıçta)}$ \\
Yerçekimi İvmesi & $: 9,81 \mathrm{~m} / \mathrm{sn}^{2}$ \\
Ortalama Kütle & $: 0,4993 \mathrm{~kg}$ \\
Net İtki (Net Kuvvet) & $: 145,88 \mathrm{kgm} / \mathrm{sn}^{2}$ \\
\end{tabular}


Karaca, N., Karagön, A., Keskin, K., Kuş, A., Sever, M. \& Göker, Ü. D. (2019). Hızlandırıcılar ile güçlendirilmişs su roket tasarımı, Anadolu Ögrretmen Dergisi, 3(2), 198-213, DOI: 10.35346/aod.584273

Zaman

Hizlandirılma

Hizlandırılma Sirasındaki Hız

Şişenin Sürtünme Kuvveti

Sürtünme Kuvveti
: 0,0968 sn

: 292,169 $\mathrm{m} / \mathrm{sn}^{2}$

: $28,282 \mathrm{~m} / \mathrm{sn}$

$: 0,15 \mathrm{kgm} / \mathrm{sn}^{2}$

: $0,85 \mathrm{kgm} / \mathrm{sn}^{2}$

2-HIZLANDIRICININ OLDUĞU DURUMDA PARAMETRELERİN DEĞERLERİ (Roketin Ana Gövdesi İçin Parametrelerin Değerleri Değişmeyecektir)

Başlangıç Basıncı (Hızlandırıcı)

Son Basınç (Hızlandırıcı)

$\Delta P$ (Hizlandırıcı)

Ortalama Kütle Akış Hızı (Hızlandırıcı)

Çıkış Hızı (Hızlandırıcı)

İtki (Hızlandırıcı)

Suyun Hacmi (Hızlandırıcı)

Suyun Kütlesi (Hızlandırıcı)

Ortalama Kütle

Net İtki (Net Kuvvet)

Zaman

Hizlandirılma

Hızlandırılma Sırasındaki Hız

$$
\begin{aligned}
& : 8,5 \mathrm{psi} \\
& : 1,36 \mathrm{psi} \\
& : 4,93 \mathrm{psi}=3,339 \times 10^{4} \mathrm{~N} / \mathrm{m}^{2} \\
& : 2,768 \mathrm{~kg} / \mathrm{sn} \\
& : 8,02 \mathrm{~m} / \mathrm{sn} \\
& : 22,199 \mathrm{kgm} / \mathrm{sn}^{2} \\
& : 0,18 \mathrm{litre} \\
& : 0,1796 \mathrm{~kg} \\
& : 0,6744 \mathrm{~kg} \\
& : 188,56 \mathrm{kgm} / \mathrm{sn}^{2} \\
& : 0,2524 \mathrm{sn} \\
& : 279,5967 \mathrm{~m} / \mathrm{sn}^{2} \\
& : 70,57 \mathrm{~m} / \mathrm{sn}
\end{aligned}
$$

3-HIZLANDIRICININ OLDUĞU DURUMDA PARAMETRELERİN DEĞERLERİ (Roketin Ana Gövdesi İçin Parametrelerin Değerleri Değişmeyecektir)

Başlangıç Basıncı (Hızlandırıı)
Son Basınç (Hızlandırıcı)
$\Delta P$ (Hızlandırııı)
Ortalama Kütle Akış Hızı (Hızlandırıcı)
Çıkış Hızı (Hızlandırıcı)
İtki (Hızlandırıcı)
Suyun Hacmi (Hızlandırıcı)
Suyun Kütlesi (Hızlandırıcı)
Ortalama Kütle
Net İtki (Net Kuvvet)
Zaman
Hızlandırılma
Hızlandırılma Sırasındaki Hız

$$
\begin{aligned}
& : 8,5 \mathrm{psi} \\
& : 1,36 \mathrm{psi} \\
& : 4,93 \mathrm{psi}=3,399 \times 10^{4} \mathrm{~N} / \mathrm{m}^{2} \\
& : 2,768 \mathrm{~kg} / \mathrm{sn} \\
& : 8,02 \mathrm{~m} / \mathrm{sn} \\
& : 22,199 \mathrm{kgm} / \mathrm{sn}^{2} \\
& : 0,18 \mathrm{litre} \\
& : 0,1796 \mathrm{~kg} \\
& : 0,7642 \mathrm{~kg} \\
& : 209,88 \mathrm{kgm} / \mathrm{sn}^{2} \\
& : 0,2524 \mathrm{sn} \\
& : 274,64 \mathrm{~m} / \mathrm{sn}^{2} \\
& : 69,32 \mathrm{~m} / \mathrm{sn}
\end{aligned}
$$




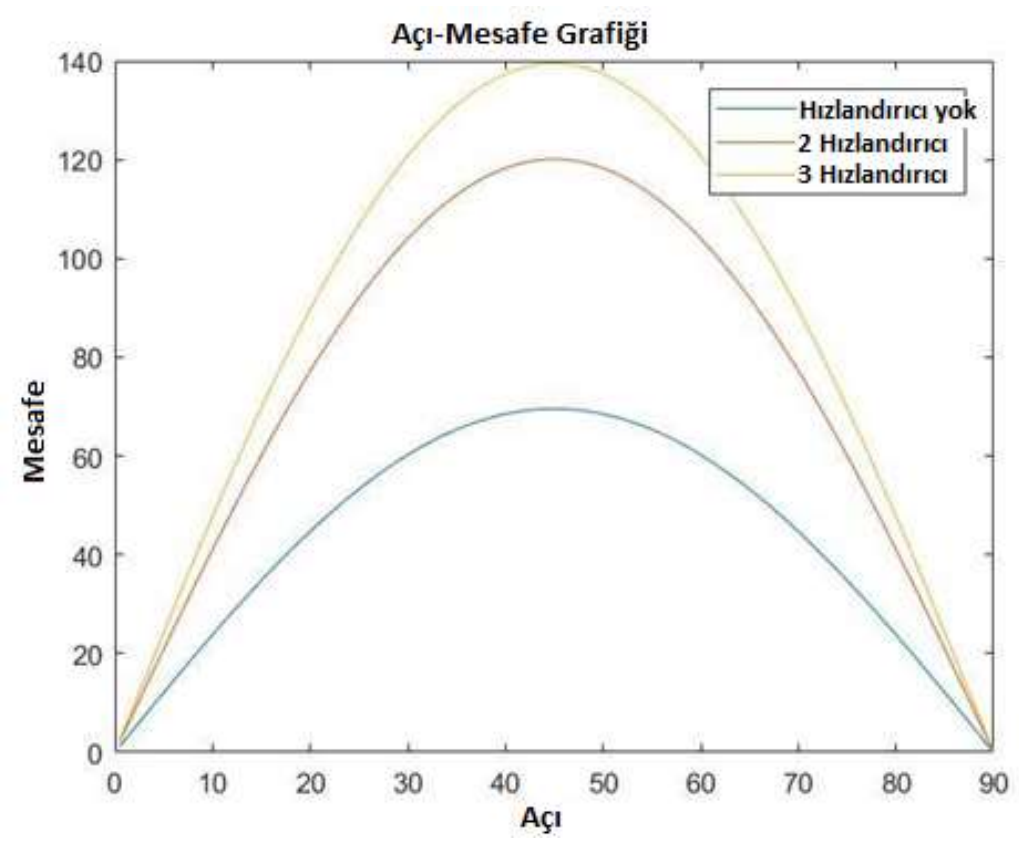

Şekil 4. Hızlandırıcı olmadan, 2-hızlandırıcılı ve 3-hızlandırıcılı su roketinin verilen ilk açıya göre atış uzaklığının değişimi gösterilmektedir.

Yukarıdaki şekilden görüleceği gibi verilen aynı açı değerlerinde, en uzak menzile ulaşacak olan 3hızlandırıcıya sahip roket olacaktır; yine 2-hızlandırıcılı ve 3-hızlandırıcılı roketler arasındaki menzil farklarının çok olmadığı görülmektedir. Hâlbuki hiç hızlandırıcısı olmayan roketin uzaklaşma mesafesi oldukça az olduğu şekilde gayet net bir biçimde görülmektedir.

$$
F_{n e t}-m g=\frac{1}{2} g t^{2}
$$

formülünü kullanarak ve yukarıda hesapladığımız $F_{\text {net }}$ değerlerini bu formülde yerine koyarsak üç farklı durum için maksimum yükselme zamanlarını hesaplayabiliriz. Buna göre; herhangi bir hızlandırıcı olmadığında verdiğimiz parametreler doğrultusunda maksimum çıkış zamanı $t=5,36 s$; 2-hızlandırıcı olduğunda maksimum çıkış zamanı $t=6,09 \mathrm{~s}$ ve 3-hızlandırıcı olduğunda çıkış zamanı $t=6,42 \mathrm{~s}$ olacaktır.

$$
x=V \cdot t
$$

formülünü kullanarak da en yüksek itkiye ulaştıklarında sahip oldukları hızları ve bu hızlarda ulaştıkları maksimum çıkış sürelerini kullanarak yaklaşık kaç metreye kadar roketimizin gideceğini teorik olarak hesaplayabiliriz. Böylece, $x$ (hızlandırıcı yok) $=151,6 m ; x(2-$ hızlandırıcı) $=429.8 m$ ve $x$ (3hızlandırıcı) $=445 \mathrm{~m}$. olarak bulunmuştur. 


\section{TARTIŞMA VE ÖNERÍLER}

$\mathrm{Bu}$ çalışma lise öğrenimi seviyesindeki öğrencilerin, fizik dersinde rahatlıkla uygulamaya koyabilecekleri su roketinin yapımına ilişkindir. Makalemizin başlangıcında temel olarak bir roketin tasarımına ilişkin genel bilgiler verilmiş olup, sonrasında asıl konumuz olan hızlandırıcılara sahip su roketinin nasıl işlediği konusuna değinilmiştir. Bu çalışmanın önemi hızlandırıcılara sahip su roketinin uygulama olarak çok fazla yapılmamış olmasıdır. Hâlihazırda bu makalede, bu roketin hazırlanabilmesi için gerekli tüm parametreler verilmiştir. Lise öğrencilerimizin tek yapacağı bu parametreleri kullanarak hızlandırıcılara sahip su roketini hayata geçirmektir. Eğer model olarak böyle bir su roket yapılırsa kullanılacak parametreler bizim verdiğimiz değerlerle gayet iyi sonuçlar verecektir.

Öğrenci bahsi geçen bilgiler ışığında, 4 yıl boyunca gördüğü bütün fizik konularının tekrarını yapmış olacak, tekrarını yaptığı bu konuları yorumlama ve birbiri ile bağdaştırma yeteneği kazanacak, teorik olarak roket bilgisi ve tasarımına hâkim olacak, el becerilerini geliştirecek, teorik ve uygulama arasındaki süreci etkili bir şekilde kullanabilmeyi başaracaktır. Bu kazanımları elde ederken gereken uygulama süreci, deneyi yaptıracak olan öğretmen tarafından belirlenen süreyi öğrencilerin etkili bir şekilde kullanabilmelerine bağlıdır. Bu da öğretmen ve öğrenci arasındaki koordineli çalışmanın etkili bir şekilde uygulanabilmesine olanak verirken, öğrenciye grup çalışma alışkanlığı becerisi de kazandıracaktır.

$\mathrm{Bu}$ çalışma yapılırken, öğrencinin çalışmanın merkezinde olmasına dikkat edilmelidir. Öğretmen burada sadece rehber olarak ve deneyin kurulum aşamasında malzeme alımlarında öğrenci ile birlikte hareket etmelidir. Roketin tasarım aşamaları hâlihazırda detaylı bir şekilde anlatılmıştır. Roketin düzgün bir şekilde çalışabilmesi için bu tasarım aşamalarının aynı sırayla takip edilmesi gerekmektedir ve makalede bahsedilen malzemelerin birebir aynısı kullanılmalıdır. Roket iyi bir şekilde tasarlanmazsa, aerodinamik kuvvetler rokete başka yönlerde etki ederek bu yönlerde hareket etmesini, ya da takılmasını ya da en kötü senaryo ile patlaması ile sonuçlanabilir. Bu patlama olayı, su roketinin en önemli dezavantajıdır. $\mathrm{Bu}$ nedenle, kesinlikle deney yapım aşamasında malzemeler dikkatli bir şekilde seçilmeli ve mutlaka proje öğretmeninin gözetiminde yapılmalıdır.

\section{KAYNAKÇA}

De Podesta, M. (2007). A Guide to Building and Understanding the Physics of Water Rockets. National Physical Laboratory (Version 1.02), England.

Karagön, A., Karaca, N., Keskin, K. \& Kuş, A. (2019). Hızlandırıcılar (Boosters) ile Güçlendirilmiş Su Roketi Tasarımı. Lisans Bitirme Tezi. Millî Savunma Üniversitesi, Hava Harp Okulu, Havacılık ve Uzay Mühendisliği Bölümü, Hava Harp Okulu Yayınları, İstanbul.

http://www.aircommandrockets.com/howitworks_1.htm https://www.ppmhcharterschool.org/ourpages/auto/2016/8/15/43286719/Bottle\%20Rocket\%2 0Calculations.ppt 